\section{A bicuspid aortic valve sign in the ascending aorta: An acute circumferential type 1 aortic dissection with intimo-intimal intussusception}

In acute aortic dissection, the dissection flap is generally oriented along the long axis of the aorta. Circumferential dissection is a rare clinical condition of aortic dissection, which is also known as intimo-intimal intussusception. A circumferentially dissected intimal flap of the ascending aorta may prolapse either distally into the aortic arch or proximally into the left ventricle. The characteristic appearance of intimo-intimal intussusceptions on computed tomography includes a short flap in the aortic root and windsock linear or curvilinear filling defects in the aortic arch. A61-year-old man with a history of hypertension and tobacco smoking presented to the emergency department with sudden-onset retrosternal chest pain. On examination, the patient's body mass index is over $35 \mathrm{~kg} / \mathrm{m}^{2}$. Skeptical ST segment and T wave changes were seen on electrocardiography. Handheld echocardiography device was used to assess the heart in the emergency department. Examination was suboptimal due to morbid obesity. Ejection fraction was normal, and we could not see any flap. Troponin at 0 and 2 hours was normal. Afterward, the patient underwent cardiac computed tomography (CCT) for further investigation. Coronary artery calcium score was 0 . Coronary arteries were normal. We saw a myocardial bridge in mid

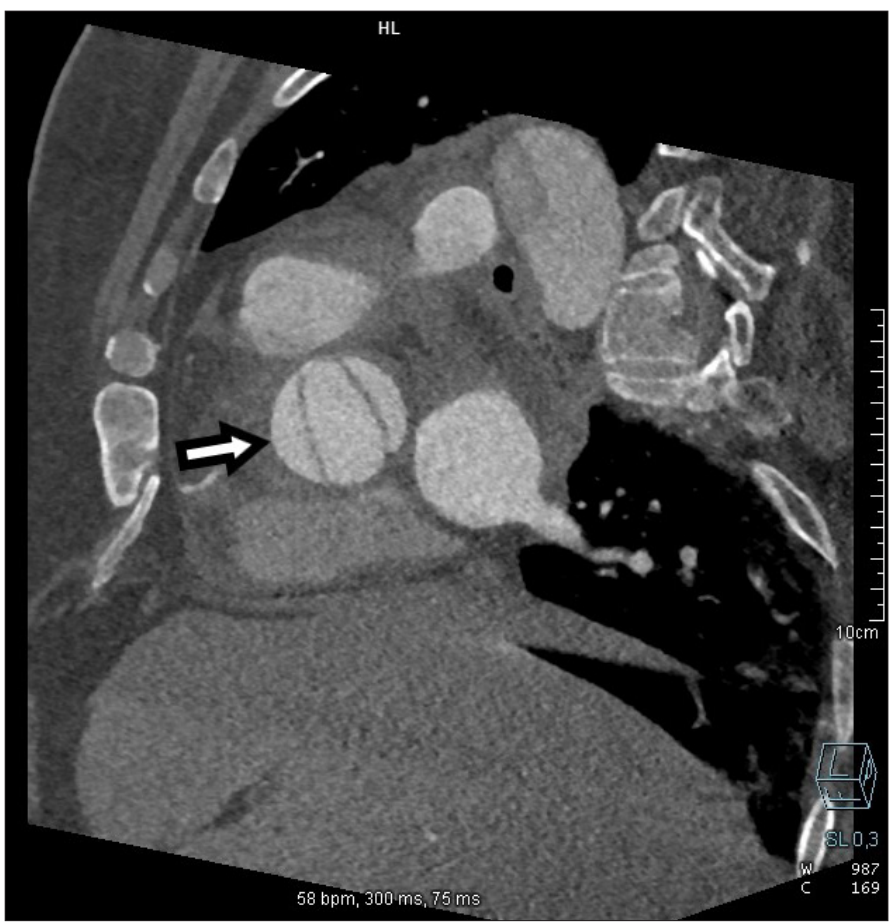

Figure 1. Bicuspid aortic valve appearance in the ascending aorta

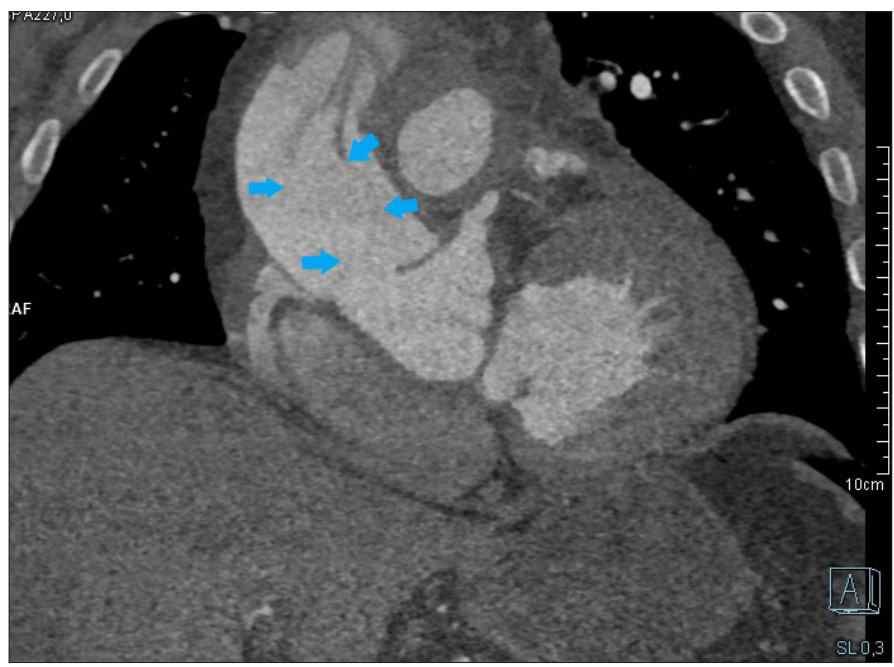

Figure 2. Windsock sign

left anterior descending artery. Contrast-enhanced CCT images demonstrated type 1 acute aortic dissection starting immediately after the origin of the coronary arteries and extending down into the descending aorta (Video 1). CCT also revealed the circumferential dissection, which is extended to the aortic arch with intussusception of the intimal layer (Fig. 1 and 2; Videos 2 and 3). The patient underwent an emergency surgery.

Informed consent: Written informed consent was obtained from the patient.

Video 1. Axial contrast-enhanced computed tomography demonstrates the coronary arteries and dissection flap

Video 2. Systolic phase of contrast-enhanced computed tomography demonstrates native tricuspid aortic valve of patient and bicuspid aortic valve-like appearance in the ascending aorta which is happened due to circumferential aortic dissection

Video 3. Windsock sign. Contrast-enhanced computed tomography cine image shows windsock sign

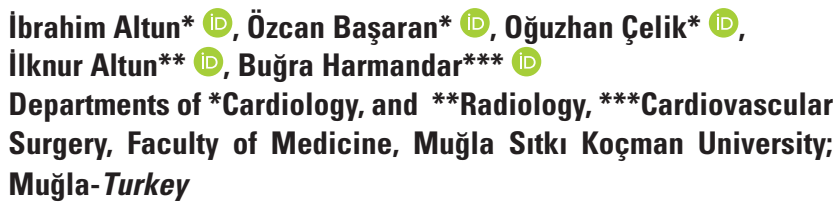

Address for Correspondence: Dr. Ibrahim Altun, Muğla Sıtkı Koçman Üniversitesi Tıp Fakültesi, Kardiyoloji Anabilim Dalı, 48000 Muğla-Türkiye Phone: +90 2522115174

E-mail: ibrahim_altun@yahoo.com (C) Copyright 2021 by Turkish Society of Cardiology Available online at www.anatoljcardiol.com DOI:10.5152/AnatolJCardiol.2021.12901 